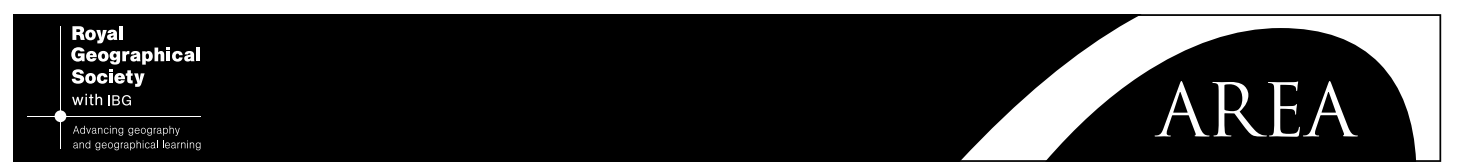

\title{
From beginnings and endings to boundaries and edges: rethinking circulation and exchange through electronic waste
}

\author{
Josh Lepawsky* and Charles Mather,** \\ *Department of Geography, Memorial University, St John's, Newfoundland, Canada A1B-3X9 \\ Email: jlepawsky@mun.ca \\ **Department of Geography, Environmental Management and Energy Studies, University of Johannesburg, \\ South Africa
}

Revised manuscript received 9 December 2010

\begin{abstract}
This paper discusses research on electronic waste in Canada and Bangladesh. We engage with ongoing debates in geography and the broader social sciences on the need to move beyond linearity in the analysis of commodity/value chains and global production networks. Our analysis suggests that the problem of linearity may be an artefact of theoretical and methodological presuppositions, which explains its longevity as an issue in methodological approaches and empirical research. Recent theoretical insights from actor network theory, combined with our own research on electronic waste, provide a potential solution to the problem of linearity. Our research points to the need for a focus on 'actions', not just 'things', in tracing economic activity. This signals a shift away from beginnings and endings in production network approaches to analyses that are concerned with boundaries and edges.
\end{abstract}

Key words: Bangladesh, Canada, follow-the-thing, e-waste, linearity, commodity chains

\section{Introduction}

But where exactly are the beginnings and ends of such a story? And where are the edges? (Cook et al. 2006, 657)

Matters grow from the middle, and from many places. But one also has to start somewhere. (Law 2002, 1; original emphasis)

Where should we start? As always, it is best to begin in the middle of things, in medias res. (Latour 2005, 27)

The ideas in this paper emerge from studying the travels of electronic waste - the ever-increasing detritus of the information age (Lepawsky and McNabb 2010). Where is it produced? What happens to it after it is gotten rid of? Where does it go? We tried following it (Appadurai 1986; Cook 2004; Cook et al. 2006). Bangladesh. We flew to Dhaka, spent 4 months tracking what we thought was e-waste, but we couldn't find any. We found used printers. Old monitors (tons and tons of them). Hard-drives from the US embassy and Exxon. Old silicon chips, motherboards and piles of circuitry. Amidst all this stuff we could hardly find any waste. Almost everything had value. Every object. Every component. Every material. They were all being bought and sold, assembled, disassembled and reassembled. The material assemblages of people, places and things proliferated (Latour 1999 2005; Law 2007 2008; Marx 1999; Verran 2009). ${ }^{1}$ They also dwindled into their constituent materials - plastics, glass, metals. Plastic printer chasses were smashed by hand and hammer, but not because these were garbage. The plastic shards were collected, sorted, baled and hefted down the street. Then they were sold. Money changed hands. Materials moved. All those bags of plastic shards were washed, then sorted by hand into categories of colour and hardness. They were washed again in a machine like an industrial dough mixer. Then they were ground into chunks, melted, extruded like gooey spaghetti while a man sliced off the noodles of plastic coming out of the machine to cool in water. Then the grinding happened. Out came the pellets. Not done yet. Some of this was bagged and sold to the plastic wholesalers down the street. The rest went right next door to a hot plastic press, manned by a single male worker, churning out CD and DVD cases, one by one, dozen after 
dozen. Some of these cases sold domestically; others were exported. To China. To India. Where were we? What were we witnessing? What we do know is that we were not where we expected to be. We expected we would end up in dumpsites, in piles of waste. Instead, we wound up in production sites. We hadn't followed things consumed, used up and ejected from the economy - we were right in the middle of it. Was this the end of a global production network? Or the beginning of one?

In this paper we situate our work on e-waste within the debates and discussions on the problem of linearity in commodity/value chain frameworks. Geographers have been at the forefront of the critique, suggesting that these frameworks lead to understandings of economic activity that are overly economistic, linear and unidirectional (e.g. Leslie and Reimer 1999; Hughes 2000). The call has been to embed commodity/value chains in their social, spatial and embodied contexts (e.g. Hudson 2008a; Coe et al. 2008). Production and exchange systems are not linear, as the framework seems to imply, but are instead characterised by circuits, networks and meshworks of economic activity. Yet despite these calls to move beyond linearity, analytical approaches in the commodity/value chain tradition remain implicitly linear and unidirectional, and alternative frameworks remain under theorised (Gregson et al. 2010a). Case studies refer to points of 'final consumption', implying the terminus of a beginning. Or they refer to moving 'up', 'down', 'forward' or 'backward' along value chains or global production networks, implying vertically and/or horizontally arranged beginnings and endings. We argue that we might be in a better position to account for the wider 'gamut' of economic activity (Hudson 2008a, 422) - including waste, its uneven dispersal and accumulation in people's bodies and environments, as well as waste's travels back into regimes of value (Gille 2007) - if we could unbracket the beginnings and endings of exchange and circulation in theoretical and methodological terms. This would involve becoming more sensitive to the 'on-going-ness' of economic activity, a shift that requires, we argue, different theoretical and methodological approaches. ${ }^{2}$

Through our work on e-waste we argue for the need to jettison beginnings and endings in value chains and global production networks. Instead of beginnings and endings we advocate for studies of circulation and exchange that search for boundaries and edges. Boundaries and edges are not pre-defined. Boundaries and edges are the results of relations. As such they are to be explained and what explains them are actions that order. Stated as generally as possible, boundaries and edges are effects of ordering relations. We cannot know in advance where (or if) we will find them, but they emerge at performed sites (Schatzki 2002) where practices and the affordances of objects and materials mingle. When searching for boundaries and edges we can follow actions, but in advance of analysis we need to remain 'as undecided as possible on which elements will be tied together, on when they will start to have a common fate, on which interests will eventually win over which' (Latour $1987,175)$. If the action ceases, so do the boundaries and edges. If the action is rearranged, so are the boundaries and edges. They are constituted in action. The action includes the knowledge practices of the researcher(s), i.e. the theoretical and methodological practices involved in defining research questions. Boundaries and edges are sites of transformation and, as such, sites-in-the-making not sites ready-made. Boundary- and edge-making is order-making, not mess-making.

Our argument about boundaries and edges draws on a broader conversation about materiality and performativity occurring in the science and technology studies literature (e.g. Çalışkan and Callon 2009; MacKenzie 2006; Law 2008; Latour 2005) and some geographers' engagements with it (e.g. Barnes 2008; Bingham 1996; Gregson et al. 2010a 2010b; Hinchliffe 2001). At its most general, the conversation proposes that what things are and how they are arranged (i.e. ontologies) are inseparable from how we go about knowing about them (i.e. epistemologies). Hence, the nexus between ontology and epistemology is an effect of relational practices that are material and meaningful or 'material-semiotic' (Law 2007). To ground our more theoretical claims, in the rest of the paper we detail some examples of the travels of 'e-waste' derived from ethnographic fieldwork in two distant, but connected, places: Bangladesh and Canada. In both countries, 'e-waste' is moved along a variety of conduits (Gregson et al. 2007) through which it is transformed into various sorts of value. Bangladesh is a recipient of e-waste from Canada, but the journey from Canada to Bangladesh transforms these objects and materials into value. At the same time, Canadian firms also process e-waste into commodity grade materials sold on the world market as inputs into industrial production. We show how thinking in terms of boundaries and edges can help understand these travels that constitute circulation and exchange. Our paper begins with the problem of linearity in global commodity/value chains. It then unbrackets the architecture of beginnings and endings inherent in these approaches and makes an argument for the analytical utility of boundaries and edges for studying practices of economisation (Çalışkan and Callon 2009 2010) and beyond.

\section{Commodity/value chains, global production networks and the critique of linearity}

The problem of linearity in commodity/value chain research has in many ways defined geography's contribu- 
tion to debates on the use of this framework to understand globalising economic activity. In the late 1990s Leslie and Reimer criticised the framework for ignoring the 'multiple and shifting connections between sites' (1999, 403). Linearity in commodity chain analysis privileged certain groups with agency at the end of the chain (e.g. 'Western' consumers), yet ignored the role of those at the beginning of the chain who may be both producers and consumers. Leslie and Reimer called for an approach to commodity chains that recognised the 'interconnected flows not only of materials but also of knowledges and discourses' (1999, 416). Hughes' (2000) research on the Kenyan cut flower trade extended the critique of linearity. Through her case study, Hughes argued that the often unidirectional linearity of commodity chain approaches... imposes analytical constraints' (2000, 177). Her work was concerned with mapping the range of different actors involved in the cut flower trade. By moving beyond the linear approach Hughes was able to analyse these as 'complex webs of interdependence rather than fixed, vertical and unidirectional relationships' $(2000,178)$. In this way her work traced the 'multi-stranded connections forged between a variety of significant and interrelated actors' $(2000,179)$. One solution to the problem of linearity has been to introduce the idea of 'circuits of culture' that ostensibly 'refuse to recognize beginning and endpoints' in the movement of commodities between production, distribution, and consumption (2000, 177). A circuits of culture approach, it has been argued, can enrich our understandings of commodities, their multidirectional journeys, and offer us a thicker description of the attachment of meaning to goods. Yet even in Hughes' (2000) early call to forgo beginnings and endings there is an implicit linearity. Such analyses typically detail the contextual meanings of commodities in consumption, and they trace the movement of ideas and knowledge up and down the chain, but they continue to see chains as having discreet beginnings (in design and manufacture) and endings (in final consumption).

The global production network (GPN) approach has contributed to the critique of linearity in commodity/value chain approaches. Through GPNs economic activity is understood not as a sequence of value creation, but as a 'meshwork' of interconnected activity (Coe et al. 2008; Henderson et al. 2002). The linearity of commodity/value chain analysis is seen in the GPN literature as a 'major weakness' and economic activities are 'better conceptualized as being highly complex network structures in which there are intricate links - horizontal, diagonal, as well as vertical - forming multidimensional, multilayered lattices of economic activity' (Henderson et al. 2002, 442). The network approach therefore allows GPN analyses to identify a wide range of non-firm actors in the production of commodities and, unlike commodity/value chains, 'GPNs strive to go beyond such linearity to incorporate all kinds of network configuration' (Coe et al. 2008, 272). Jennifer John's (2006) work on the global production network for video games is a good example of the GPN approach. Drawing on primary interviews with console manufacturers, Johns traces the emergence of complex and spatially embedded networks of software and hardware firms. Yet as is the case with the broader range of commodity chain approaches, Johns' research presupposes a necessary beginning with financing as opposed to, for example, designs on a drawing board, or oil extraction for the plastic that will become the packaging for the video games. In the same way, she presupposes a necessary ending at the cash register as opposed to, for example, the 'ongoing' role of the commodity in homes or as electronic waste after disposal.

A more recent critique of linearity has emerged that takes as its starting point the malleability of commodities, especially after the point of final consumption. Commodity chain analyses typically trace the production and consumption of commodities that are stable and unchanging (Gregson et al. 2010a). Gregson et al.'s (2010a) research traces commodities that are coming apart and are being transformed. For example, through a case study of ship breaking in Bangladesh, Gregson et al. (2010a) are able to trace how parts of the ship are recycled to produce furniture for middle-class households in cities like Dhaka. By exploring the lives of commodities after final consumption these authors unveil the ongoing use and transformation of goods that happens after a standard commodity/ value chain or GPN analysis would have ended. In the case of ship breaking, for example, following-the-thing involves tracking the 'unmaking' of things that are broken up into smaller commodities or transformed into new objects. In some cases the commodity itself (the ship) becomes raw material. The boat is valued not for what it is, but for what it 'might become' (Gregson et al. 2010a, 853). This neglected part of the value chain is where objects and materials are resold or transformed for a further round of consumption (Gregson 2007; Gregson et al. 2005 2007). And yet, while Gregson et al.'s (2010a) research on disassembly of things allows them to explore what materials do without relying on a problematic notion of 'final consumption', they nevertheless follow commodities that are coming apart and are incorporated into what they call the 'back-end of the value chain' (Gregson et al. 2010a, 847). A back-end to a value chain implies a front-end, and thus we are once again in the analytically problematic realm of beginnings and endings.

The decade-long effort to move beyond linearity in commodity/value chain research has provided important new methodological tools for analysing the complexity of economic activity. The case studies have demonstrated how chains are embedded in spaces, social contexts and 
bodies. Commodity production and circulation is clearly not linear, but is instead networked, meshworked and circuited, reflecting the nature of exchange in advanced capitalist economies. And we can now add a 'back end' to the value chain, where goods are discarded only to be transformed and then consumed again. Yet our work on e-waste suggests that the critique has failed to get to the underlying problem of linearity. For us linearity is not only a problem of simplifying economic activity as a linear flow (cf. Hudson 2008b); nor is it only a problem associated with removing economic activity from the spatial, social and embodied context in which it is embedded. It is, instead, a problem related to the architecture of beginnings and endings. Despite the efforts to move beyond linearity, commodity/value chain analyses remain wedded to an analysis of economic activity that has a defined beginning and end point. Gregson et al.'s work represents an important and promising move forward in that it shows how economic activity is 'ongoing'; it does not stop at a familiar point of final consumption. At the same time their work is a partial and temporary unbracketing of economic activity. One end of the chain is opened up, but only for it to close again at a new end point: the back-end of the value chain.

If economic activity is not necessarily bracketed by beginnings and endings, where does that leave us? How do we approach the analysis of economic activity? Does this mean that economic activity is chaotic and disorganised? No, it means that we need new methodological and conceptual approaches. Our research suggests that boundaries and edges, rather than beginnings and endings, offer a way forward.

\section{From beginnings and endings to boundaries and edges}

In the streets of Dhaka we kept following the things we could recognise as used and discarded electronics. We watched them get disassembled and reassembled into refurbished machines. Watched them get disassembled by hand into components and materials. Assemblages. We kept following. We crossed the Buriganga River and found the metal from circuit boards being transformed into gold and silver bars, into household hardware (see Plate 1).

The hardware got sold in Dhaka and Japan. The precious metal bars crossed back over the river and got sold to wholesalers, to jewellery makers. From there the jewellery makers in Old Dhaka churned out ornate gold and silver jewellery. Sold in Bangladesh. Exported to Singapore. To India. For weddings. For status. For love. For profit. Here we were again in the middle of it all.

We toured industrial plants devoted to recycling electronics in southern Ontario, Canada. There we found a rapidly restructuring industry. The province's electronics recycling programme had recently started. The international commodities markets were crashing in the 'Great Recession'. But here were two companies making money, turning profit from e-waste. They told us that most of the rest of the recyclers, the ones that tried to turn profits from the commodities markets, were going bankrupt (see also Levin 2009; Richtel and Galbraith 2008). The firms we visited are different. Theirs are big facilities. Shop floors of hundreds of square metres. Highly automated. Only 20 to 30 employees working on a shift. Three shifts. 24/5. Massive two-storey shredding machines. Huge grinders. Loud, noisy, hot. These companies process thousands of tons of discarded electronics per day through this heavy, industrial work. The one churns out partially processed material for smelters and other processors that turn it into energy or into commodity grade material. The other grinds and sorts it all right down to commodity grade material in house. Plastics. Glass. Metals (see Plate 2).

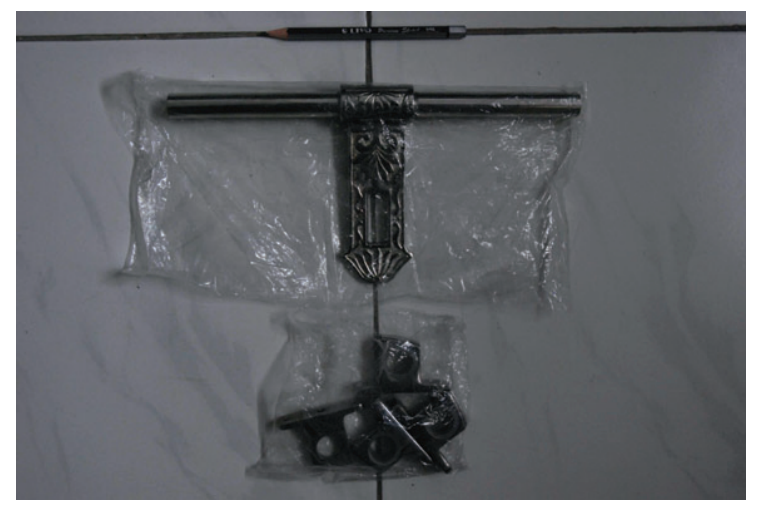

Plate 1 A lock for a gate manufactured from former e-waste and other metal scraps in Dhaka, Bangladesh Source: photograph by the authors 


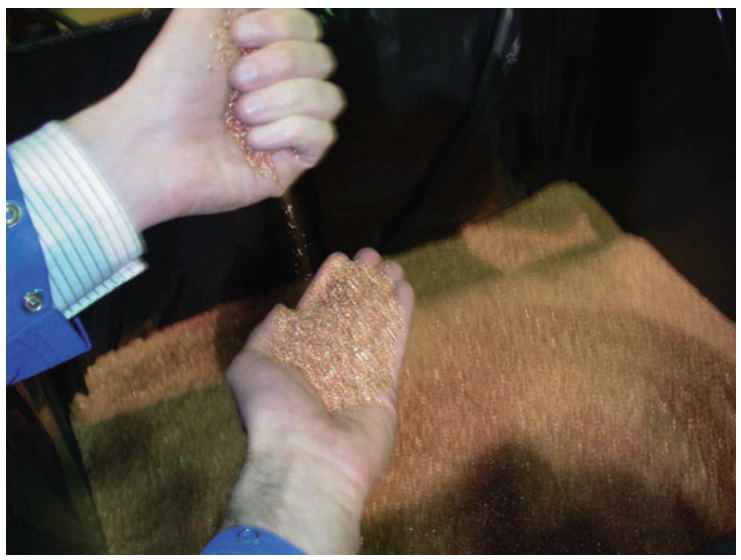

Plate 2 Former e-waste processed into commodity grade copper Source: photograph by the authors

But all this material, the thousands of tons of it, is not where either of these firms make their money. The commodities market is a fool's game. That's what they told us. The money is, as they put it, all on the front end. Sure, if the commodities markets are up, that's great, a little cream, but not where sustainable profit comes from. The sales pitch is to the banks, the retailers and the health care sector. Sustainable profit comes from charging your customers up front, 20 cents per pound of e-waste, for guaranteeing secure data destruction and that no IT equipment with the customer's brand on it will end up in an exposé about companies losing computers with private information stored on them (e.g. CBC News 2007; Unattributed 2007) or dumping e-waste in Third World countries (e.g. Höges 2009; PBS 2009; 60 Minutes, 2008). These firms in Ontario process thousands of tons of e-waste material so they can produce pieces of paper: certificates of secure data destruction. Privacy protection, certified and guaranteed. These huge industrial operations produce information about the destruction of information to mitigate liability and to manage brands.

In Ontario, just like in Dhaka, the usual organising concepts of the commodity/value chain or global production network approaches were not helping us to understand the travels of e-waste. There was no way, aside from what felt like arbitrary decisions, to say this phase is an ending and that phase is a beginning. Neither did thinking in terms of front/back-ends of value chains, nor in terms of up/down metaphors feel like anything but arbitrary impositions of directionality. For a particular participant in the action there may appear to be natural beginnings and endings. Here is Sam, a manager at one of the recycling facilities we visited in Ontario: 'To us [the company], "final resting place" means the material [formerly e-waste] has reached commodity grade status, which means it can be sold on the open market'. Note the paradox. Sam describes what is for his company an ending (i.e. there is a 'final resting place'), which is at the same time by his own definition, a beginning (i.e. a sale on the commodities market). But the ending for Sam (commodity grade raw material) is where commodity/ value chain and GPN analyses would typically begin. Thus, for actors and analysts, economic action is ordered as if there are beginnings and endings. But there is a difference between acting as if the world is ordered in a particular way and the world actually being ordered in that way: actors and analysts enact different ontological orders out of the same moment, one's ending is the other's beginning.

The more recent critique of linearity helped us understand the importance of divestment, disassembly and material affordances (Gregson et al. 2010a): in the circumstances of e-waste processing companies in Ontario objects 'come apart' into commodity grade materials (similar to the scenario in Bangladesh), but it is the destruction of objects and the subsequent production of information about their destruction from which these Ontario-based firms derive the most lucrative forms of value. 'Information' itself entails materiality (e.g. the paper certificates of secure destruction), but this is materiality of quite a different make and magnitude to that of the commodity grade metals, plastics and glass that also flow out of these firms. Out of their facilities, besides information, comes all that material formerly known as e-waste to be sold on the world commodities markets. All those materials are inputs into the planet's manufacturing industries that produce things made of glass, plastics and metals. That is, all of them. So where do we locate these Ontario-based firms? At the front-end or the back-end of the value chain? The top or the bottom? Beginning or end? Here we were again. In the middle of it all. 


\section{Boundary- and edge-making}

As we followed the travels of e-waste we began to entertain the possibility that there are no essential beginnings or endings to these stories, no inherent directionality. More importantly: if we are genuinely committed to followingthe-things, where could we plausibly stop? Boundaries and edges represent one way of overcoming the analytically problematic notions of beginnings and endings while also offering us a way to reasonably perform our studies.

Our own research practices (e.g. the formulation of research questions) had been partly responsible for formatting the ontological status of the things we wanted to follow in highly particular, partial and situated ways (i.e. as 'waste'). Like all good researchers, we read the literature and it told us e-waste is the end-point in a linear chain of production, consumption and disposal (e.g. Basel Action Network 2002; Environment Canada 2003; Greenpeace International 2005; Hicks et al. 2005). As such we had been expecting to find 'waste'. We defined our thing to follow in advance (e-waste), went to its origins and traced it along its chains to its assumed future. But that future rarely happened. Rather than finding 'waste', we kept finding 'value'. In following 'e-waste' qua waste, we were bringing its reality as waste into existence, performing it (Barnes 2008). Yet, the reality we presupposed kept failing (we kept finding 'value', not 'waste'), so we had to entertain the possibility of multiple coincident realities (Law 2010). We realised that rather than following things assumed to have an essential ontology as this or that type of thing, we needed to think in terms of distributed and transitory ontologies that are effects of intermingled material affordances and practices. The ontological action includes those people and things that we follow, but also ourselves as researchers, for example, in terms of how we formulate research questions, in other words, our epistemologies (see Çalışkan and Callon 2009; Latour 2005; Law 2008).

So what to do? Did our search for waste leave us with a mess? No. Thirty years ago, Thompson (1979) argued that in order to understand value, one had also to understand 'rubbish'. Not synonymous with waste or garbage, Thompson's notion of 'rubbish' is a material-semiotic placeholder, a category that objects may move into and out of (see also Appadurai 1986). Rubbish-value relations '[make] nonsense of the idea of beginnings and ends' (Thompson 1979, 113). We found resonances between Thompson's ideas and contemporary notions of materialsemiotics in the science and technology studies literature (e.g. Law 2007 2008; Latour 2005; Çalışkan and Callon 2009). We rethought our analysis that was initially premised on the idea of following things and instead considered what we might learn if we followed actions; if we studied not waste and value, but wasting and valuing. But the actions of wasting and valuing seemed unending and, if so, how were we to realistically bound our research about the geographies of e-waste? What we came to realise was that we could follow actions until the things they enacted were enacted as something else (Mol 2002); where, for example, copper wires or gold circuitry became unrecognisable as electronics but were now, for example, copper ingots or gold bars. These moments of transformation, the sites where they occurred, and our research about them constitute some of the boundaries and edges of the geographies of e-waste.

We came to understand these boundaries and edges not as phenomena simply out there in the world, but as material relational effects of the intermingling of people (including us as practising researchers), places and things as well as how we went about knowing about their dispositions. Had we arbitrarily imposed directionality by insisting that this or that moment was a beginning or ending of a commodity/value chain or global production network, the objects and materials we followed and the practices through which they are enacted would have counted for nothing, since we would be presuming to know in advance who and what was relevant and how they are arranged (see Latour 2005). As a consequence of thinking in terms of boundaries and edges, we could avoid arbitrary designations of beginnings, endings, frontends or back-ends, ups or downs; we could jettison any presuppositions about inherent directionality, without losing directionality as such. We could follow actions (of people, but also objects and materials) and their orchestration of realities, only some of which are about economisation (Çalışkan and Callon 2009 2010), yet we could still make organised sense of the geographies of e-waste. We couldn't know in advance of study when or where (or even if) we would find the boundaries or edges of e-waste. But by following the action we could recognise them as effects or achievements or arrival points at those sites multiple, distributed, uneven, but nevertheless associated - where transformation was occurring, where things were becoming something else in action. Where, for example, at multiple, distributed, uneven and associated sites gold circuitry was becoming gold bars or gold bars were becoming cash ... or jewellery... or gifts ... or love. Where, for example (and again at multiple, distributed, uneven and associated sites), lead-soldered circuit boards or plastic covered wires were becoming fumes and scrap metal ... becoming air-borne, water-borne and bloodborne toxins ... becoming ornate gate locks and household implements. These are some of the boundaries and edges of the geographies of e-waste.

\section{Conclusion}

Our paper represents a contribution to the ongoing effort to engage with the problem of linearity in the wide range of 
production network approaches employed by geographers and other social scientists. We argue that despite the commitment to undertake production chain analyses that are more networked and embedded, much analysis remains within a problematic architecture of beginnings and endings. This is partly because the method poses an ontological problem: if the analysis presupposes an end point (such as a finished commodity) to which it will subsequently return, then the research is very likely to uncover an architecture of beginnings and endings that is a methodological artefact rather than a necessary feature of economic action. What boundaries and edges offer are ways to keep going, to keep following the action without presupposing inherent directionality. We could, for example, follow the action of e-waste-now-gold-jewellerynow-love to a wedding ceremony. And from there to ... ? Finding the boundaries and edges allows new rounds of research to emerge. At a wedding ceremony, what relevance do questions about e-waste have? Or, as lead solder becomes air-, water- and blood-borne toxins, what relevance do questions about commodity chains have? Boundaries and edges allow us to keep following the action and make our research practices relevant to different, yet associated, sites.

Our findings suggest broader lessons for geographers and other social scientists interested in what the nonlinear, multidirectional travels of things can disclose about the worlds we share and how they are ordered. We suggest such studies could benefit from the following methodological questions and principles as thinking technologies (Haraway 2004). In advance of following actions, remain as undecided as possible about what will be associated together and about when and where common trajectories will emerge (Latour 1987). Proceed as if we do not know in advance of the analysis what the geographical is made up of (see Latour 2005, 138). Instead, proceed by asking what is the geographical made up of? What is associated together? What is acting when we are acting? Where are we acting when we are acting? As a matter of methodological principle follow actions, not just the things that transport and transform them and so make a difference to them (Latour 2005).

\section{Acknowledgements}

We thank Mostaem Billah and Chris McNabb for crucial research assistance, Cecile Badenhorst and two anonymous referees for their incisive comments on an earlier version of this paper. We also thank the Social Sciences and Humanities Research Council for research support. The usual disclaimers apply.

\section{Notes}

1 Verran's discussion of 'assemblage' notes it as a useful, if problematic, translation of Deleuze and Guattari's notion of 'agencement'. Like Verran, we are signalling assemblage as it used in versions of actor-network theory.

2 We thank Reviewer 1 for drawing our attention to the critical issue of 'ongoingness'.

\section{References}

60 Minutes 2008 Following the trail of toxic e-waste (http://www.cbsnews.com/stories/2008/11/06/60minutes/ main4579229.shtml) Accessed 28 February 2011

Appadurai A 1986 The social life of things: commodities in cultural perspective Cambridge University Press, Cambridge

Barnes T J 2008 Making space for the economy: live performances, dead objects, and economic geography Geography Compass 2 1432-8

Basel Action Network 2002 Exporting harm: the high-tech trashing of Asia (http://www.ban.org/main/library.html) Accessed 27 October 2005

Bingham N 1996 Object-ions: from technological determinism toward geographies of relations Environment and Planning $D$ : Society and Space 14 635-57

Çalışkan K and Callon M 2009 Economization, part 1: shifting attention from the economy towards processes of economization Economy \& Society 38 369-98

Çalışkan K and Callon M 2010 Economization, part 2: a research programme for the study of markets Economy and Society 39 $1-32$

CBC News 2007 Owner of Winners, HomeSense says hacker stole customer info (http://www.cbc.ca/consumer/story/2007/ 01/18/winnersbreach.html) Accessed 18 November 2009

Coe N M, Dicken P and Hess M 2008 Global production networks: realizing the potential Journal of Economic Geography 8 271-95

Cook I 2004 Follow the thing: papaya Antipode 36 642-64

Cook I et al. 2006 Geographies of food: following Progress in Human Geography 30 655-66

Environment Canada 2003 Baseline study of end-of-life electrical and electronic equipment in Canada Environment Canada, Ottawa

Gille Z 2007 From the cult of waste to the trash heap of history: the politics of waste in socialist and postsocialist Hungary Indiana University Press, Bloomington IN

Greenpeace International 2005 Recycling of electronic wastes in China \& India: workplace \& environmental contamination (http://www.e-takeback.org/press_open/export_waste.htm) Accessed 27 October 2005

Gregson N 2007 Identity, mobility, and the throwaway society. Environment and Planning D-Society \& Space 25 682-700.

Gregson N, Crewe L and Metcalfe A 2005 Disposal, devaluation and consumerism: or how and why things come not to matter University of Sheffield, Sheffield

Gregson N, Metcalfe A and Crewe L 2007 Moving things along: the conduits and practices of divestment in consumption Transactions of the Institute of British Geographers 32 187-200

Gregson N, Crang M, Ahamed F, Akhter N and Ferdous R 2010a Following things of rubbish value: end-of-life ships, 'chockchocky' furniture and the Bangladeshi middle class consumer Geoforum 41 846-54 
Gregson N, Watkins H and Calestani M 2010b Inextinguishable fibres: demolition and the vital materials of asbestos Environment and Planning A 42 1065-83

Haraway D J 2004 The Haraway reader Routledge, New York

Henderson J, Dicken P, Hess M, Coe N and Yeung H W-C 2002 Global production networks and the analysis of economic development Review of International Political Economy 9 436-64

Hicks C, Dietmar R and Eugster M 2005 The recycling and disposal of electrical and electronic waste in China - legislative and market responses Environmental Impact Assessment Review 25 459-71

Hinchliffe S 2001 Indeterminacy in-decisions - science, policy and politics in the BSE (bovine spongiform encephalopathy) crisis Transactions of the Institute of British Geographers 26 182-204

Höges C 2009 How Europe's discarded computers are poisoning Africa's kids (http://www.spiegel.de/international/world/0, 1518,665061,00.html) Accessed 4 December 2009

Hudson R 2008a Cultural political economy meets global production networks: a productive meeting? Journal of Economic Geography 8 421-40

Hudson R 2008b Material matters: taking cultural political economy to the next level (http://www.thewasteoftheworld.org/ docs/Material_mattersRH.pdf) Accessed 13 September 2008

Hughes A 2000 Retailers, knowledges and changing commodity networks: the case of the cut flower trade Geoforum 31 175-90

Johns J 2006 Video games production networks': value capture, power relations and embeddedness Journal of Economic Geography 6 151-80

Latour B 1987 Science in action Harvard University Press, Cambridge MA

Latour B 1999 Pandora's hope Harvard University Press, Cambridge MA

Latour B 2005 Reassembling the social: an introduction to actor network theory Oxford University Press, Oxford

Law J 2002 Aircraft stories: decentering the object in technoscience Duke University Press, Durham NC

Law J 2007 Actor network theory and material semiotics (http://www.heterogeneities.net/publications/ Law2007ANTandMaterialSemiotics.pdf) Accessed 23 March 2010
Law J 2008 The materials of STS (http://www.heterogeneities. net/publications/Law2008MaterialsofSTS.pdf) Accessed 23 March 2010

Law J 2010 Reality failures (http://www.heterogeneities.net/ publications/Law2010RealityFailures5.pdf) Accessed 4 April 2010

Lepawsky J and McNabb C 2010 Mapping international flows of electronic waste The Canadian Geographer 54 177-95

Leslie D and Reimer S 1999 Spatializing commodity chains Progress in Human Geography 23 401-20

Levin D 2009 China's big recycling market is sagging New York Times Online (http://www.nytimes.com/2009/03/12/business/ worldbusiness/12recycle.html?_r=2) Accessed 12 March 2009

MacKenzie D 2006 An engine, not a camera: how financial models shape markets MIT Press, Cambridge MA

Marx K 1999 Capital Volume 1 Zodiac, Kuhls H, Thurrott A, McDorman B, Schultz B and Gimenez $\mathbf{M}$ transcribers (http:// www.marxists.org/archive/marx/works/1867-c1) Accessed 7 October 2010

Mol A 2002 The body multiple Duke University Press, Durham $\mathrm{NC}$

PBS 2009 Ghana: digital dumping ground (http://www.pbs.org/ frontlineworld/stories/ghana804/index.html) Accessed 17 February 2009

Richtel M and Galbraith K 2008 Back at junk value, recyclables are piling up New York Times (http://www.nytimes.com/2008/ 12/08/business/08recycle.html?pagewanted=1\&hp) Accessed 8 December 2008

Schatzki T R 2002 The site of the social: a philosophical account of the constitution of social life and change Pennsylvania State University Press, University Park PA

Thompson M 1979 Rubbish theory: the creation and destruction of value Oxford University Press, Oxford

Unattributed 2007 Customer data stolen from Winners owner (http://www.thestar.com/Business/article/172249) Accessed 18 November 2009

Verran H 2009 On assemblage - indigenous knowledge and digital media (2003-2006), and HMS Investigator (1800-1805) Journal of Cultural Economy 2 169-82 